\title{
Impact of intravenous immunoglobulin on the dopaminergic system and immune response in the acute MPTP mouse model of Parkinson's disease
}

\author{
Isabelle St-Amour ${ }^{1,2,3}$, Mélanie Bousquet ${ }^{1,2}$, Isabelle Paré ${ }^{3}$, Janelle Drouin-Ouellet ${ }^{1,4}$, Francesca Cicchetti ${ }^{1,4}$,
} Renée Bazin ${ }^{2,3}$ and Frédéric Calon ${ }^{1,2^{*}}$

\begin{abstract}
Intravenous immunoglobulin (IVlg) is a blood-derived product, used for the treatment of immunodeficiency and autoimmune diseases. Since a range of immunotherapies have recently been proposed as a therapeutic strategy for Parkinson's disease (PD), we investigated the effects of an IVIg treatment in a neurotoxin-induced animal model of PD. Mice received four injections of MPTP $(15 \mathrm{mg} / \mathrm{kg})$ at 2-hour intervals followed by a 14-day IVlg treatment, which induced key immune-related changes such as increased regulatory T-cell population and decreased $\mathrm{CD} 4^{+} / \mathrm{CD}^{+}$ ratio. The MPTP treatment induced significant $80 \%$ and $84 \%$ decreases of striatal dopamine concentrations $(P<0.01)$, as well as $33 \%$ and $40 \%$ reductions in the number of nigral dopaminergic neurons $(P<0.001)$ in controls and IVlg-treated mice, respectively. Two-way analyses of variance further revealed lower striatal tyrosine hydroxylase protein levels, striatal homovanillic acid concentrations and nigral dopaminergic neurons $(P<0.05)$ in IVlg-treated animals. Collectively, our results fail to support a neurorestorative effect of IVIg on the nigrostriatal system in the MPTP-treated mice and even suggest a trend toward a detrimental effect of IVlg on the dopaminergic system. These preclinical data underscore the need to proceed with caution before initiating clinical trials of IVIg in PD patients.
\end{abstract}

Keywords: Intravenous immunoglobulin, Parkinson's disease, Immunity, Neurodegeneration, MPTP, Dopamine

\section{Background}

Central and peripheral activation of the innate and adaptive immune systems have been associated with neurodegenerative diseases such as Parkinson's disease (PD). Elevated concentrations of cytokines, such as TNFo, IL-1 $\beta$, IL-6, TGF $\beta$ (transforming growth factor-beta) and IFN $\gamma$ have been reported in mouse models of dopaminergic (DAergic) denervation $[1,2]$ as well as in the substantia nigra pars compacta (SNpc) and striatum of $\mathrm{PD}$ patients [2-6]. Similarly, increased concentrations of macrophage migration inhibition factor, IL-2, IL-6, TNF $\alpha$ and TNF $\alpha$ receptor- 1 have been measured in the blood

\footnotetext{
*Correspondence: Frederic.Calon@crchul.ulaval.ca

'Centre de Recherche du CHUL (CHUQ), Axe Neurosciences, T2-05, 2705, boulevard Laurier, Québec, QC, Canada G1V 4G2

${ }^{2}$ Faculté de Pharmacie, Université Laval, Québec, QC, Canada G1V OA6

Full list of author information is available at the end of the article
}

of PD patients [7-13]. Migration of both $\mathrm{CD}^{+}$(helper) and $\mathrm{CD}^{+}$(cytotoxic) T-lymphocytes have been identified within the SNpc of PD patients and further associated with nigrostriatal denervation in a mouse model of PD through a CD4 $4^{+}$T-cell-dependent Fas/Fas ligand (FasL) cytotoxic pathway [14]. Immunological abnormalities observed in PD patients and animal models suggest an overall disruption of the immune system in the disease, but their causal role is still highly debated. It remains to be demonstrated whether immunological abnormalities are relevant therapeutic targets for neurodegenerative disorders.

Recently, intravenous immunoglobulin (IVIg) has been proposed in the treatment of neurodegenerative diseases. The safety and tolerability profiles of IVIg have justified the initiation of phase II and phase III clinical trials in Alzheimer's disease (AD) patients and in individuals 
suffering from mild cognitive impairments (reviewed in [15]). IVIg is a therapeutic preparation of over $98 \%$ human IgG purified from the plasma of thousands of healthy donors [16-19]. Besides its routine use for a growing number of autoimmune diseases, beneficial effects of IVIg have also been reported in immunemediated neurological diseases such as chronic inflammatory demyelinating polyneuropathy, Guillain-Barré syndrome, multiple sclerosis and multifocal motor neuropathy (reviewed in [20-23]).

Although the mechanisms of action of IVIg remain only partially understood, anti-inflammatory and immunomodulatory effects have been described both in vitro and in vivo [24-28]. In theory, some of these functions could correct key immunologic defects described in PD. For example, in humans, IVIg treatments decrease plasma levels of TGF $\beta$, IL-1 $\beta$, IL-6, IL-8, IFN $\gamma$ and TNF $\alpha$ $[29,30]$, all shown to be upregulated in PD. In vitro, IVIg has also been reported to decrease phagocytosis in microglia, to modulate transendothelial cell migration, adhesion and rolling, and to interfere with the Fas/FasL cytotoxic pathway [31-34]. More recently, increased hippocampal neurogenesis following IVIg treatment has been reported in a mouse model of AD [35]. Furthermore, active and passive immunization against $\alpha$-synuclein ( $\alpha$-syn), the main component of the neuronal cytoplasmic inclusions found in PD [36,37], has been shown to reduce neuropathology and behavioral deficits in an $\alpha$-syn transgenic mouse model $[38,39]$. In line with these latter observations, antibodies specific to $\alpha$-syn have recently been isolated from IVIg [40], further suggesting a potential clinical application for the use of IVIg to achieve passive immunization in PD.

Current therapies in PD are mainly symptomatic, and no drugs have ever obtained a label of disease modification or neuroprotection from health agencies [41,42]. In light of the existing data for the benefits of IVIg in autoimmune and neurological diseases, we undertook to investigate whether such an approach could also benefit PD patients. To test this hypothesis, we evaluated whether IVIg could lead to the neurorestoration of the DAergic system after a nigrostriatal lesion. We used a post-MPTP paradigm where the IVIg treatment was delivered after the MPTP insult. This approach avoids unwanted interference of IVIg with MPTP toxicokinetics and is more representative of the typical clinical setting where the treatment is administered after the diagnosis [43].

\section{Materials and methods Reagents}

All biochemical reagents were purchased from J.T. Baker (Phillipsburg, NJ, USA) unless otherwise specified.

\section{Animals, MPTP administration and IVIg treatment}

Eight-week-old C57BL6J males (22 to $27 \mathrm{~g}$ ), purchased from Charles River Laboratories (Montréal, QC, Canada) were housed three per cage with free access to food and water. All procedures were approved by the Animal Research Committee of Laval University.

Animals were injected intraperitoneally with MPTP neurotoxin following a standard acute protocol [43-45] and were sacrificed 14 days later (Figure 1). On day 0, the mice received four injections of an $\mathrm{MPTP}-\mathrm{HCl}$ solution (15 mg free base/kg; Sigma-Aldrich, Oakville, ON, Canada) freshly dissolved in $0.9 \%$ saline, at 2 -hour intervals. To avoid that the pharmacologic intervention under study alters MPTP toxicokinetics, Jackson-Lewis and Przedborski suggested delaying the beginning of the treatment for at least 8 hours after the last MPTP injection [43]. An IVIg treatment posology of $0.4 \mathrm{~g} \times \mathrm{kg}^{-1} \times$ week $^{-1}$ has shown efficacy in a recent AD clinical trial [46]. However, the mouse metabolism is faster than that of humans, as exemplified by the IVIg half-life of 89 hours in mice (unpublished data) instead of 35 days in

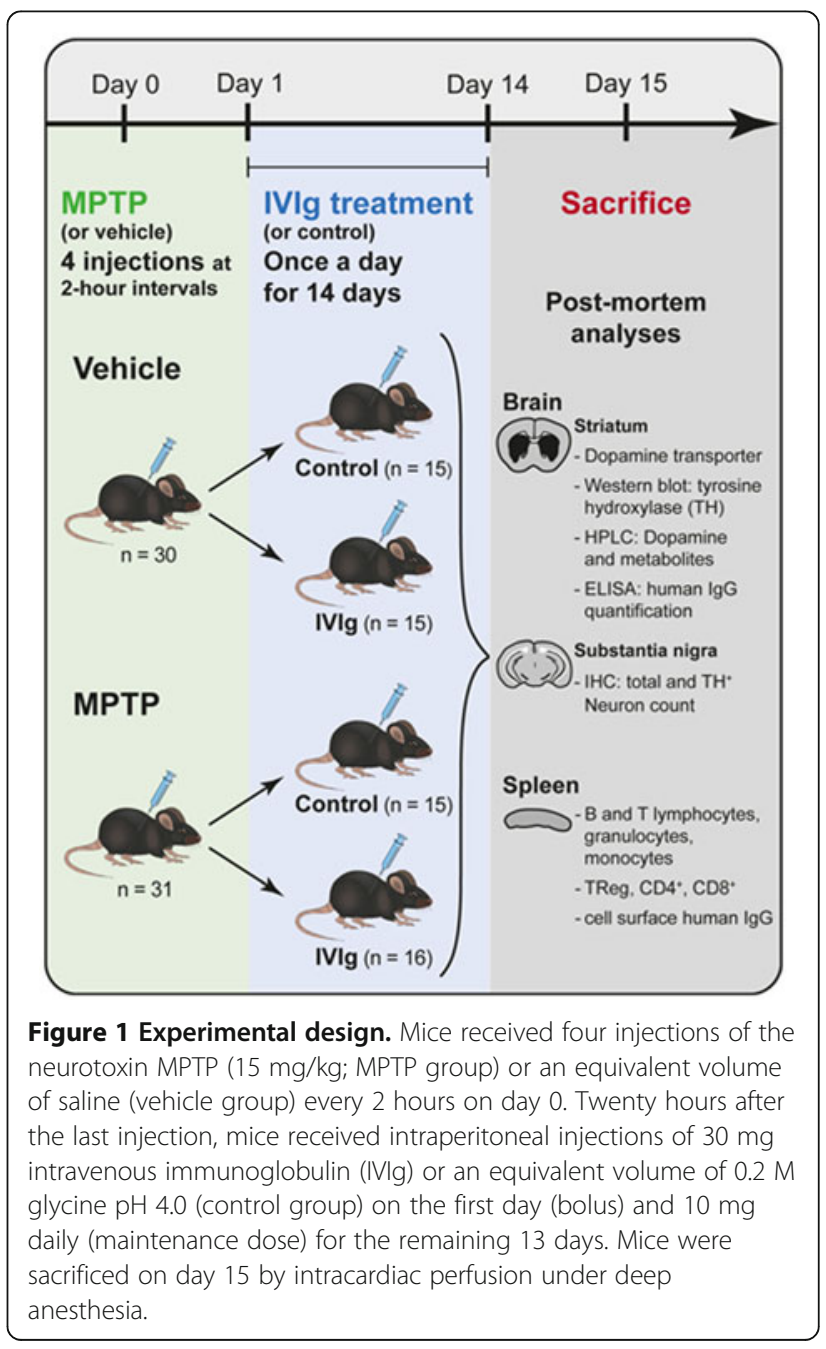


humans [17]. To match the human dosage as closely as possible, we thus selected a dose of $0.4 \mathrm{~g} \times \mathrm{kg}^{-1} \times$ day $^{-1}$. To quickly reach therapeutic concentrations, mice ( $n=15$ or 16/group) received a bolus dose of $30 \mathrm{mg}$ IVIg $(\sim 1.2 \mathrm{~g} / \mathrm{kg}$ from a $100 \mathrm{mg} / \mathrm{ml}$ human IgG solution, diluted in 0.2 M glycine pH 4.25 - Gammunex ${ }^{\mathrm{Tn}}$; Grifols, Mississauga, ON, Canada) or an equivalent volume of glycine $(0.2 \mathrm{M}, \mathrm{pH} 4.25) 20$ hours following the last MPTP injection. For the remaining 13 days, animals were injected daily with $10 \mathrm{mg} /$ day $\left(\sim 0.4 \mathrm{~g} \times \mathrm{kg}^{-1} \times\right.$ day $\left.^{-1}\right)$ IVIg or glycine (maintenance dose) for a total treatment duration of 14 days. The animals were sacrificed 2 weeks after the last MPTP injection to probe for a neurorestorative effect of IVIg on the ongoing MPTP-induced neurodegeneration of the DAergic system.

\section{Tissue preparation for postmortem analyses}

Terminal intracardiac perfusion was performed under deep anesthesia (ketamine/xylazine). After transcardiac administration of $50 \mathrm{ml}$ PBS buffer (Bioshop Canada Inc., Burlington, ON, Canada) containing protease and phosphatase inhibitors (SigmaFAST Protease Inhibitor Tablets (Sigma-Aldrich) with $50 \mathrm{mM}$ sodium fluoride and $1 \mathrm{mM}$ sodium pyrophosphate), both spleen and brain were collected. Brain hemispheres were separated: the striatum was dissected from the rostral section of the right hemisphere, snap-frozen on dry ice and stored at $-80^{\circ} \mathrm{C}$. The caudal section was post-fixed in $4 \%$ paraformaldehyde $\mathrm{pH} 7.4$ and sliced with a freezing microtome (coronal brain sections of $25 \mu \mathrm{m}$ ). The left hemisphere was snap-frozen in 2-methyl-butane and stored at $-80^{\circ} \mathrm{C}$ for cryostat coronal brain sections $(12 \mu \mathrm{m})$. Splenocytes were recovered from the spleen following mechanical disaggregation, frozen at $-80^{\circ} \mathrm{C}$ in a cryoprotective medium (Iscove's Modified Dulbecco's Medium supplemented with $20 \%$ fetal bovine serum and $5 \%$ dimethylsulfoxide) and kept in liquid nitrogen until further use.

\section{Spleen analyses \\ Flow cytometry}

Cell surface marker expression on splenocytes were analyzed using AF647-conjugated anti-CD3 (clone 17A2; BD Biosciences, Mississauga, ON, Canada), eFluor 780conjugated anti-B220 (clone RM4-5; BD Biosciences), PE-Cy7-conjugated anti-CD4 (clone GK1.5; eBioscience, San Diego, CA, USA), eFluor 450-conjugated anti-CD8a (clone 53-6.7; eBioscience), APC-conjugated antiCD11b (clone M1/70; BD Biosciences), FITC-conjugated anti-Gr1 (LY-6 G clone RB6-8C5; eBioscience) or relevant isotypic controls in PBS-1\% BSA. For human IgG detection, splenocytes were labeled with $\mathrm{PE}$-conjugated anti-CD45 and FITC-conjugated anti-human IgG. For regulatory T-lymphocyte analyses, splenocytes were stained on ice for 30 minutes with PE-conjugated antiCD25 (clone PC61.5; eBioscience) and APC-conjugated anti-CD4 (clone RM4-5; BD Bioscience) followed by permeabilization and fixation using the Foxp3 staining buffer (eBioscience) and staining with eFluor450conjugated anti-Foxp3 (clone FJK-16s; eBioscience) following the manufacturer's instructions. Cells were acquired and analyzed using a CyFlow ML (Partec, Swedesboro, NJ, USA) cytometer and FCS express software (De Novo Software, Los Angeles, CA, USA).

\section{ELISPOT analyses}

To determine whether the injection of IVIg triggered an anti-human IgG immune response, an ELISPOT test was performed. Briefly, splenocytes were unfrozen, washed, counted, plated on human IgG-coated wells (Multiscreen ${ }^{\circledR}$ HTS filter plate; Millipore Corporation, Billerica, MA, USA) blocked with $5 \%$ fetal bovine serum and left immobile for 16 hours at $37^{\circ} \mathrm{C}, 10 \% \mathrm{CO}_{2}$ for antibody secretion. After washing the cells, anti-human specific mouse immunoglobulins were detected using a horseradish peroxidase-conjugated anti-mouse IgG (heavy and light chain specific; Jackson ImmunoResearch Laboratories Inc., West Grove, PA, USA) and TrueBlue ${ }^{\text {rm }}$ Peroxydase Substrate (KPL, Mandel Scientific, Gaithersburg, MD, USA). Each spot was counted under a dissection microscope and considered a single anti-human specific $B$ cell. Results from mice treated with IVIg were compared with controls.

\section{Brain analyses \\ Striatum}

ELISA and Western immunoblot analyses Each striatum was homogenized in 8 volumes of lysis buffer per milligram of tissue $\left(150 \mathrm{mM} \mathrm{NaCl}, 10 \mathrm{mM} \mathrm{Na} \mathrm{HPO}_{4}\right.$, $0.5 \%$ sodium dodecylsulfate, $0.5 \%$ sodium deoxycholate, $1 \%$ Triton X-100 containing Complete ${ }^{\text {Tx }}$ protease inhibitors cocktail (Roche, Indianapolis, IN, USA), $10 \mu \mathrm{g} / \mathrm{ml}$ pepstatin A and $1 \mathrm{mM}$ each of sodium fluoride and sodium orthovanadate as phosphatase inhibitors) and was sonicated three times for five 1-second pulses. The solution was centrifuged at $100,000 \times g$ for 20 minutes at $4^{\circ} \mathrm{C}$, and the supernatant was retrieved and kept at $-80^{\circ} \mathrm{C}$ for ELISA and immunoblotting. The protein concentration was determined using a bicinchoninic acid assay (Pierce, Rockford, IL, USA).

An ELISA specific to human IgG was utilized to determine the striatal concentration of IVIg using goat anti-human IgG Fc-specific antibodies (Jackson ImmunoResearch Laboratories Inc.). For immunoblot analyses, proteins $(20 \mu \mathrm{g} / \mathrm{samples})$ were heated at $95^{\circ} \mathrm{C}$ for $5 \mathrm{~min}$ utes in Laemmli's loading buffer and separated by SDSPAGE on a $10 \%$ polyacryamide gel, before transferring 
to a polyvinylidene fluoride membrane (Immobilon- $\mathrm{P}^{\mathrm{rm}}$; Millipore Corporation) that was blocked in 5\% nonfat dry milk, 0.5\% BSA, 0.1\% Tween 20 in PBS buffer as previously described [47]. Tyrosine hydroxylase $(\mathrm{TH})$ protein was detected using rabbit anti-TH (1:5,000, \#P40101; Pel-Freez, Rogers, AR, USA) primary antibody followed by horseradish peroxidase-labeled secondary antibody and chemiluminescence reagents (Lumiglo Reserve; KPL) as previously described [48]. Membranes were also probed for $\beta$-actin (1:10,000; Applied Biological Materials Inc., Richmond, BC, Canada) as a control for protein load. Band intensities were quantified using a KODAK Imaging Station 4000 MM Digital Imaging System (Molecular Imaging Software version 4.0.5f7; Carestream Health, Rochester, NY, USA).

Catecholamine and indolamine quantification Ten slices of $20 \mu \mathrm{m}$ rostral striata were homogenized in 200 $\mu \mathrm{l}$ of $0.1 \mathrm{~N}$ perchloric acid (Mallinckrodt Baker, Phillipsburg, NJ, USA) and centrifuged at $12,000 \times g$ for $10 \mathrm{~min}$ utes at $4^{\circ} \mathrm{C}$. HPLC with electrochemical detection was used to evaluate the concentration of dopamine (DA), 3,4-dihydroxyphenylacetic acid (DOPAC) and homovanillic acid (HVA) in striatal supernatant, as previously described [48]. Briefly, $50 \mu \mathrm{l}$ supernatant were injected into the chromatograph consisting of a Waters 717 plus autosampler automatic injector, a Waters 1525 binary pump equipped with an Atlantis dC18 column, a Waters 2465 electrochemical detector, and a glassy carbon electrode (Waters Ltd, Lachine, QC, Canada). The electrochemical detector was set at $10 \mathrm{nA}$. The mobile phase consisted of $47.8 \mathrm{mM} \mathrm{NaH} \mathrm{PO}_{4}, 0.9 \mathrm{~m} \mathrm{M}$ sodium octyl sulfate, $0.4 \mathrm{mM}$ ethylenediamine tetraacetic acid, $2 \mathrm{mM}$ $\mathrm{NaCl}$ and $8 \%(\mathrm{v} / \mathrm{v})$ methanol at $\mathrm{pH} 2.9$ and was delivered at $0.8 \mathrm{ml} /$ minute. Peaks were identified using Breeze Software (Waters Ltd) and HPLC quantifications were normalized to protein concentrations.

\section{Dopamine transporter quantification}

DA transporter (DAT) was evaluated with $3 \beta-\left(4-{ }^{125} \mathrm{I}-\right.$ iodophenyl) tropane-2-carboxylic acid isopropylester ( ${ }^{125}$ I-RTI-121, 2,200 Ci/mmol; NEN-DuPont, Boston, MA, USA), as previously described $[45,49]$. Slidemounted brain sections were preincubated at room temperature for 30 minutes in phosphate buffer $\mathrm{pH} 7.4$ followed by a 90-minute incubation with $20 \mathrm{pM}{ }^{125} \mathrm{I}$ RTI-121. Nonspecific binding was determined in the presence of $0.1 \mu \mathrm{M}$ mazindol (Novartis Pharmaceuticals, Dorval, QC, Canada). Sections were then washed with phosphate buffer followed by distilled water, dried overnight and exposed to Kodak BioMax film for 16 hours (Sigma-Aldrich). Densitometry was quantified using the Image J Analysis Software (National Institutes of Health, USA). The average labeling for each area was calculated from the mean of six adjacent brain sections from the rostral striatum of a $1 / 10$ series of the same animal.

\section{Substantia nigra}

Immunohistochemistry To visualize $\mathrm{TH}$-positive neurons of the SNpc, sections were first incubated for 30 minutes in $3 \% \mathrm{H}_{2} \mathrm{O}_{2}$ and blocked with $5 \%$ normal goat serum and $0.1 \%$ Triton in PBS for 30 minutes. After an overnight incubation with an anti-TH antibody (1:5,000; Pel-Freez), sections were washed three times in PBS and incubated for 1 hour with biotin-conjugated anti-rabbit antibody. After further washing, the sections were placed in a solution containing ABC (Elite kit; Vector Laboratories, Burlington, ON, Canada) for 1 hour at room temperature. The bound peroxidase was revealed with $0.5 \mathrm{mg} / \mathrm{ml} \mathrm{DAB}$ (Sigma-Aldrich) and 0.01\% hydrogen peroxide in $0.05 \mathrm{M}$ Tris $(\mathrm{pH}$ 7.6). The reaction was stopped by extensively washing the sections in PBS. The sections were counterstained with cresyl violet, dehydrated and cover slipped. Photomicrographs were taken with a Microfire 1.0 camera (Optronics, Goleta, CA, USA) linked to an E800 Nikon 274 microscope (Nikon Inc., Québec, QC, Canada) using the imaging software Picture Frame.

Stereological counts of TH-positive and cresyl-violetstained cells The total number of $\mathrm{TH}$-positive and $\mathrm{TH}$ negative neurons of the SNpc was quantified stereologically on seven sections of a $1 / 5$ series, as previously described [48-50]. Selected sections, at intervals of 125 $\mu \mathrm{m}$, were counted in a blinded fashion by two independent investigators using Stereo Investigator software (MicroBrightfield, Williston, VT, USA) integrated to an E800 Nikon 274 microscope. After delineating the SNpc at low magnification ( $4 \times$ objective) a point grid was overlaid onto each section. Stained cells (TH-positive or cresyl-violet stained) with a clearly defined and intact nucleus were counted using the optical fractionator method at higher magnification (20x objective). The counting variables were as follows: distance between counting frames, $150 \mu \mathrm{m} \times 150 \mu \mathrm{m}$; counting frame size, $75 \mu \mathrm{m}$; guard zone thickness, $1 \mu \mathrm{m}$. Cells were counted only if they did not intersect forbidden lines.

\section{Statistical analyses}

Statistical analyses were performed using the JMP software (version 9.0.2; SAS Institute Inc., Cary, IL, USA) and Prism 4.0c (GraphPad Software Inc., La Jolla, CA, USA). A Bartlett test was first performed on all data to verify equal variance. In cases of equal variance, statistical differences were determined using one-way analysis of variance (ANOVA) followed by post-hoc test (Tukey's or Dunnett's) for comparison between groups. When 
variances were unequal, a Welch ANOVA followed with Dunnett's multiple comparison test was employed. If a Gaussian distribution could not be assumed, the Kruskal-Wallis nonparametric test was used followed by Dunn's post-test. The survival curves were compared using the log-rank test. To evaluate the overall effects of IVIg in both the vehicle and MPTP groups, two-way ANOVAs were also performed.

\section{Results}

\section{Health status and IVIg treatment}

Weight loss and mortality is commonly observed in the acute MPTP protocol, particularly shortly after injections of the toxin [43]. In this study, MPTP administration led to the death of $5 / 31$ mice between days 4 and 5 after toxin injection (Figure 2A): one mouse in the MPTP-control group $(n=15)$ and four of the MPTPIVIg-treated animals $(n=16)$. MPTP-induced lethality was thus significantly higher in the MPTP-IVIg group. These animals were excluded from all postmortem analyses. An increase in weight loss, paralleling the mortality rate, was also observed in surviving animals from the MPTP-IVIg group (Figure 2B,C), specifically at day 2 . Despite the fact that IVIg alone did not lead to increased lethality or weight loss in the vehicle group, the treatment tended to potentiate the detrimental effect of MPTP and thus impact the general health status of the treated animals.

\section{IVIg administration increases the proportion of the regulatory $\mathrm{T}$ cells in the spleen}

We next evaluated the effects of IVIg on the splenic population of regulatory $\mathrm{T}$ cells (Tregs), which are known to be upregulated by IVIg in patients and mouse models of inflammatory disorders [51-54]. Indeed, Tregs suppress immune activation and maintain immune homeostasis and tolerance [55,56], while protecting nigrostriatal afferents in an MPTP mouse model of PD [57-59]. Our data revealed that repeated injections of IVIg resulted in an increase in the percentage of splenic Tregs. A $21.6 \%$ increase of CD $25^{+} /$Foxp $^{+}$Tregs in the $\mathrm{CD}^{+}{ }^{+}$population following IVIg treatment was observed, but only in the vehicle group (Figure 3A,B; $7.55 \%$ vs. 9.17\% CD25 ${ }^{+} /$Foxp $^{+}$gated on $\mathrm{CD}^{+}$, vehicle-control and vehicle-IVIg respectively). MPTP treatment also induced a $26.1 \%$ increase in the relative Treg population (Figure 3A,B; MPTP-control: 9.52\% Treg), but the IVIg treatment did not further increase the Treg population in the MPTP group. We also evaluated the subpopulation of $\mathrm{iCOS}^{+} \mathrm{CD} 4^{+} \mathrm{T}$ cells (Figure 3 ), as they have previously been associated with IVIg-induced regulation of the central nervous system (CNS) inflammatory response [54], but no significant effects were observed in any of the treated groups. Granulocyte, monocyte,

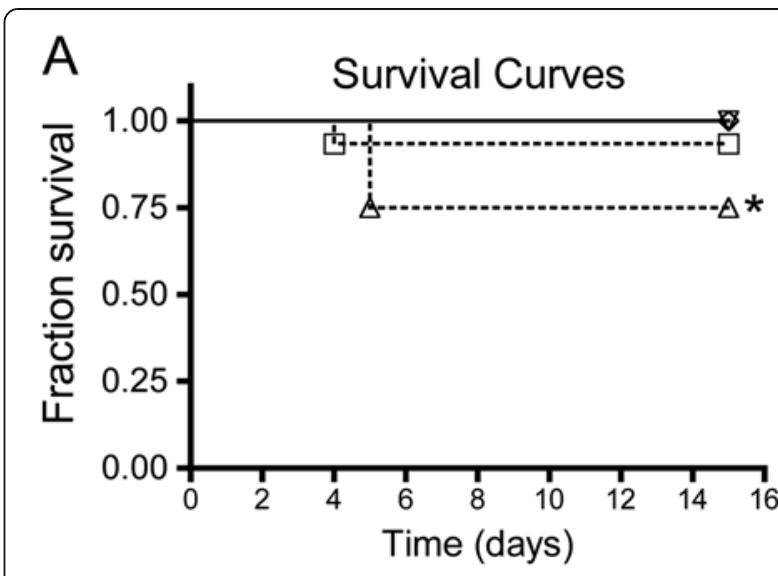

B
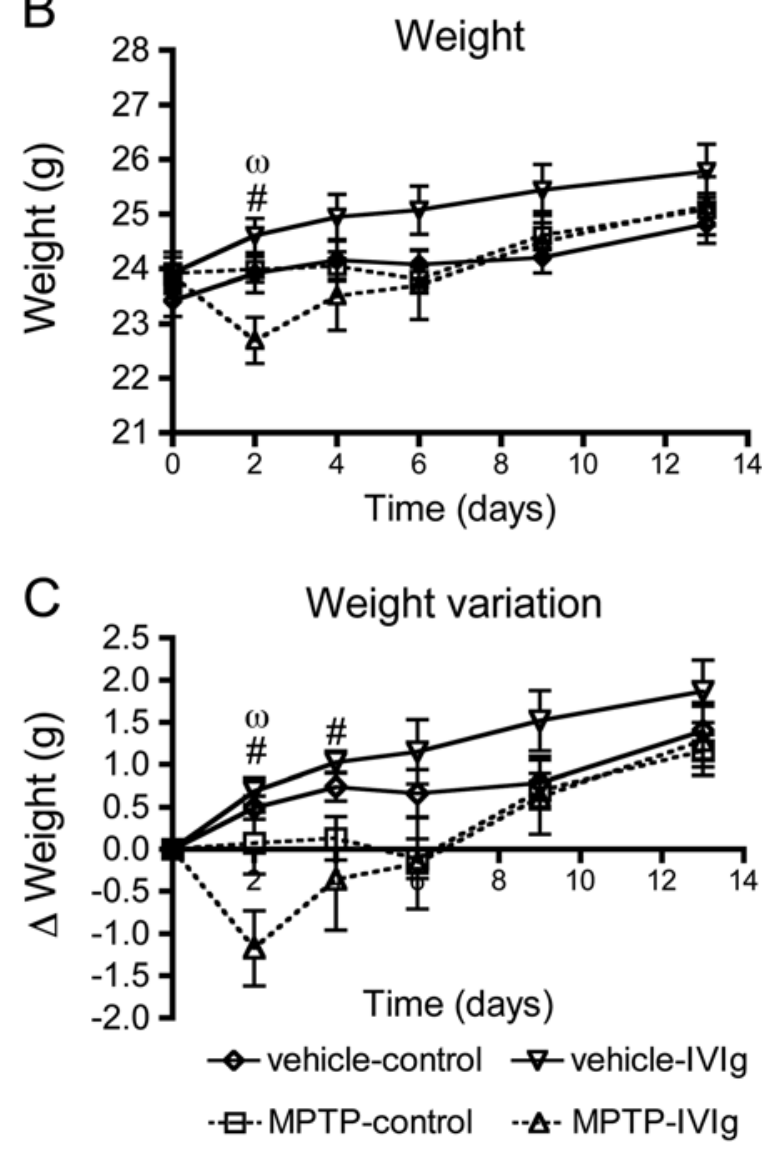

Figure 2 Intravenous immunoglobulin injection increases MPTP-related weight loss and lethality. Lethality and weight loss rate were monitored throughout the experiment. (A) Mortality rate induced by MPTP treatment was higher in the intravenous immunoglobulin (IVIg) group. (B) Weight and (C) weight variation of the animals excluding all the mice that died before the end of the protocol. Data are presented as mean \pm standard error of the mean of 12 to 15 animals. Statistical analysis: (A) log-rank test was performed to compare survival curves, ${ }^{*} P<0.05$ MPTP-IVlg versus vehicle groups. (B),(C) One-way analysis of variance followed by Tukey's multiple comparison test, ${ }^{\#} P<0.05$ MPTP-IVIg versus vehicleIVlg group, ${ }^{\omega} P<0.05$ MPTP-IVIg versus MPTP-control group. 


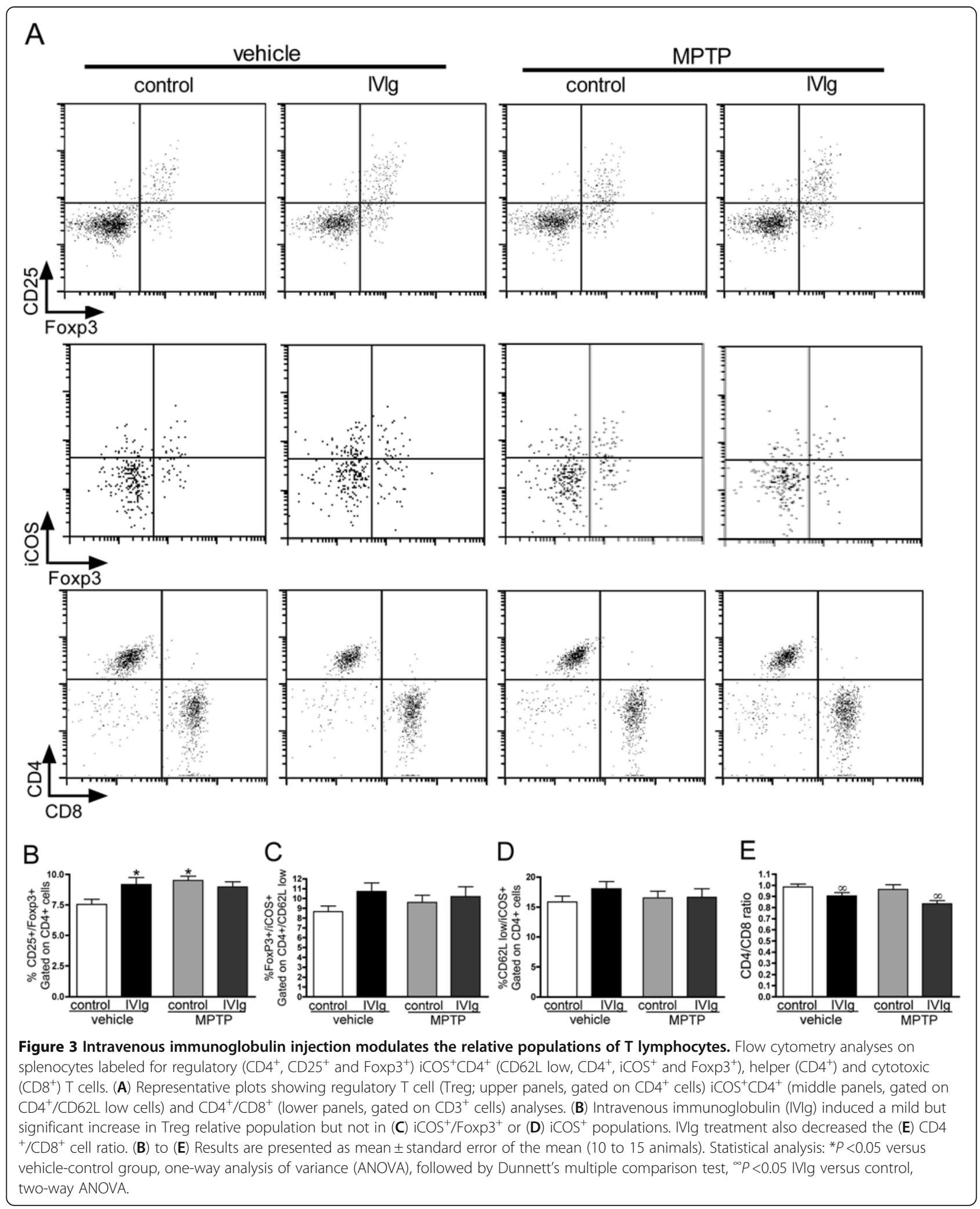


B-lymphocyte and T-lymphocyte populations in the splenocytes of all animals were also analyzed but no statistical differences were observed between groups (data not shown). However, IVIg injections also led to a significant decrease in the $\mathrm{CD} 4^{+} / \mathrm{CD}^{+} \mathrm{T}$ lymphocytes ratio in the vehicle and MPTP groups compared with controls, respectively (Figure 3 ).

\section{Bioavailability of IVIg in brain and periphery}

We further measured the bioavailability of IVIg in the brain and spleen of IVIg-treated mice. Detectable amounts of extracellular IVIg were present on splenic $\mathrm{CD} 45^{+}$leukocytes as evaluated by flow cytometry (Figure $4 \mathrm{~A}, \mathrm{~B}$ ) with a mean fluorescence intensity of $14.54 \pm 0.32$ in the IVIg groups versus a baseline autofluorescence intensity of 6.72 \pm 0.21 for controls. Using a human specific anti-IgG ELISA, we also determined that the concentrations of IVIg in striatal homogenates were as high as $5.8 \pm 0.2$ and $5.5 \pm$ $0.3 \mathrm{ng}$ IVIg/mg tissue in the vehicle-IVIg and MPTP-IVIg groups, respectively (Figure $4 \mathrm{C}$ ). These data suggest that detectable amounts of human IgG are present in the brain and on the surface of circulating leukocytes after a 14-day treatment with IVIg in this parkinsonian mouse model.

\section{IVlg induces a minimal immune response}

To determine whether repeated IVIg injections induced an anti-human IgG specific adaptive immune response, ELISPOT analyses were performed ( $n=10$ per group). With this technique, we were able to assess the number of splenocytes secreting a specific anti-human IgG antibody in control and IVIg groups, 14 days post MPTP. Although there was a significant increase in the number of splenic cells reactive to human IgG following IVIg administration (two-way ANOVA, $P<0.05$ ), it remained very low. The amount of anti-human IgG specific cells was below 4/100,000 splenocytes in all animals. The absolute number of antibody secreting cells per spleen was $445 \pm 173$ and $154 \pm 98$ for the vehicle-IVIg and MPTPIVIg group (mean \pm standard error of the mean) versus $34 \pm 22$ and $23 \pm 12$ for the vehicle-control and MPTPcontrol groups. For comparison purposes, in mouse models of autoimmune diseases, the reported absolute number of antibody secreting cells to myeloperoxidase,
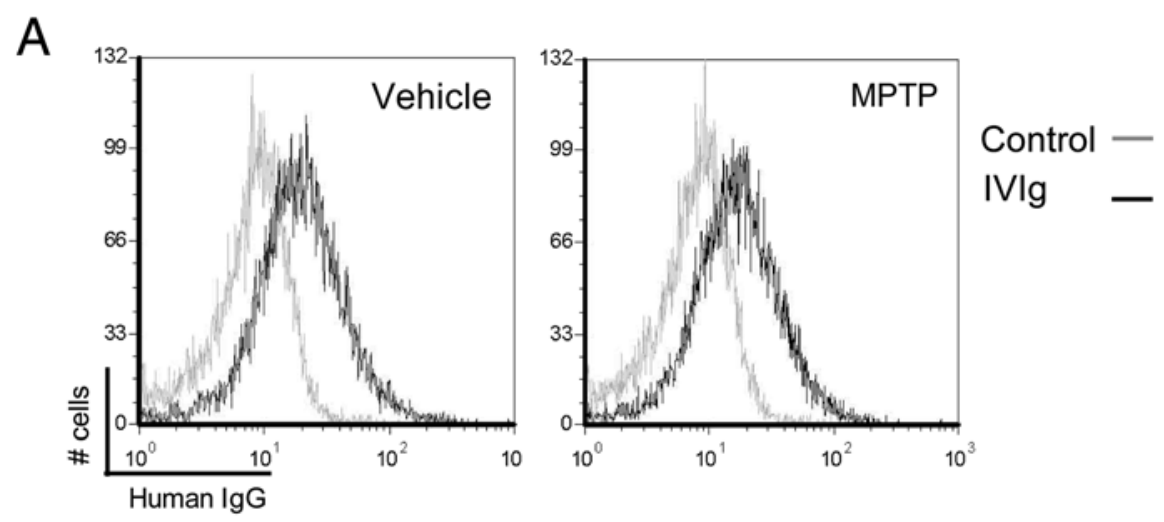

B

IVlg on CD45+ splenocytes
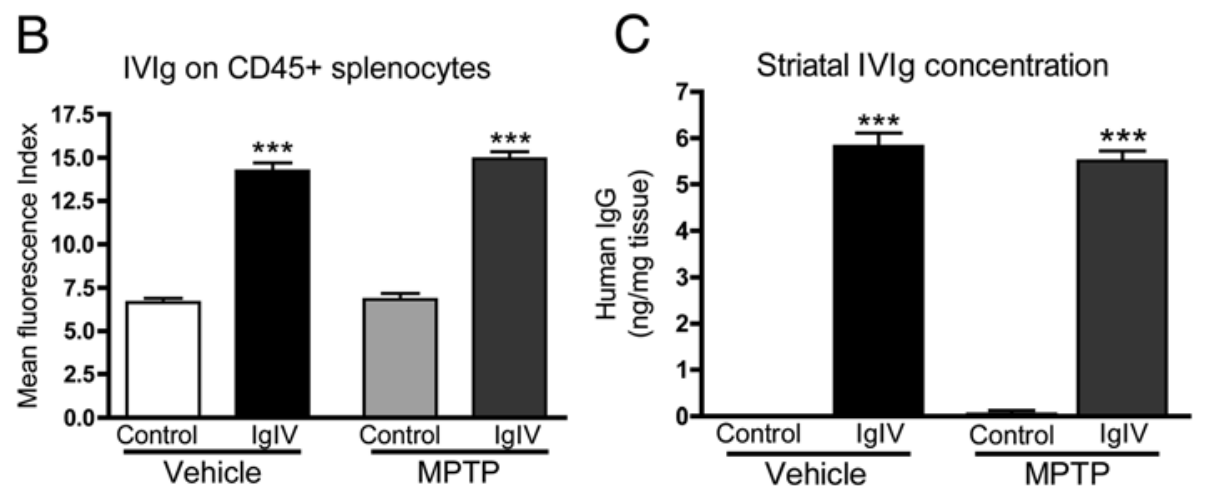

Figure 4 Detectable amounts of intravenous immunoglobulin in the brain and splenocytes of treated mice. Human IgG concentrations were evaluated on splenocytes and in the striatum of intravenous immunoglobulin (IVIg) and control mice. (A) Representative flow cytometric analyses and (B) mean fluorescence intensity (MFI) quantification of extracellular human IgG on $\mathrm{CD}_{4} 5^{+}$splenocytes. Note that the MFI of the control groups is equivalent to isotypic control and autofluorescence (data not shown). (C) Concentrations of IVlg were measured in striatum homogenates from intracardially perfused mice using a specific ELISA. (B), (C) Data presented as mean \pm standard error of the mean of 12 to 15 animals, ${ }^{* *} P<0.001$ versus control groups, one-way analysis of variance followed by Tukey's multiple comparison test. 
nucleolin and dsDNA are higher than 11,000, 17,000 and 33,000 specific cells/spleen, respectively $[60,61]$.

\section{Effects of MPTP and IVlg on the striatal components of} the dopaminergic system

As evaluated by HPLC quantification, MPTP induced significant reductions in striatal concentrations of DA and its metabolites DOPAC and HVA, reaching 80\%, $49 \%$, and $51 \%$, respectively, in IVIg-untreated mice $(P<0.01$, one-way ANOVA; Figure 5$)$. Similarly, $84 \%$, $65 \%$, and $56 \%$ decreases of DA, DOPAC and HVA were observed in the striatum of the IVIg-MPTP mice compared with IVIg-vehicle mice (Figure 5A,B,C). When two-way ANOVAs were performed, the IVIg treatment was associated with a significant decrease in HVA and serotonin (Figure 5B,D) compared with control groups. Therefore, catecholamine data point toward the absence of a restorative effect of the IVIg treatment after the MPTP-induced nigrostriatal lesion.

A comparable $71 \%$ decrease of ${ }^{125}$ RTI-121-specific DAT binding in both controls and IVIg-treated MPTP mice compared with vehicle mice was measured in the striatum (Figure 6A,B), further supporting the lack of beneficial effects of IVIg. Moreover, TH, the ratelimiting enzyme in the catecholamine synthesis [62], was quantified in the striatum using Western immunoblot analysis. MPTP markedly depleted TH protein levels by $64 \%$ in both the MPTP-IVIg and MPTP-control groups compared with their respective controls (Figure 6C,D). IVIg treatment also led to a $16 \%$ decrease in $\mathrm{TH}$ protein levels in animals not exposed to MPTP. Two-way ANOVAs further underscored a significant decrease of striatal $\mathrm{TH}$ protein levels in IVIg-treated groups (vehicle and MPTP) as compared with controls (Figure 6C,D).

\section{Effects of MPTP and IVIg on nigral dopaminergic neuronal loss}

As expected, MPTP injections led to a significant decrease in the number of TH-positive DAergic neurons in the SNpc (Figure 7), as determined by immunohistochemistry. Stereological count of TH-positive and cresyl-violetstained neurons in SNpc revealed a 33\% reduction of $\mathrm{TH}-$ positive neurons in the MPTP-control group, whereas there was a $40 \%$ decrease in the MPTP-IVIg group (Figure 7A), as compared with their respective controls. The total number of SNpc neurons (TH-positive and
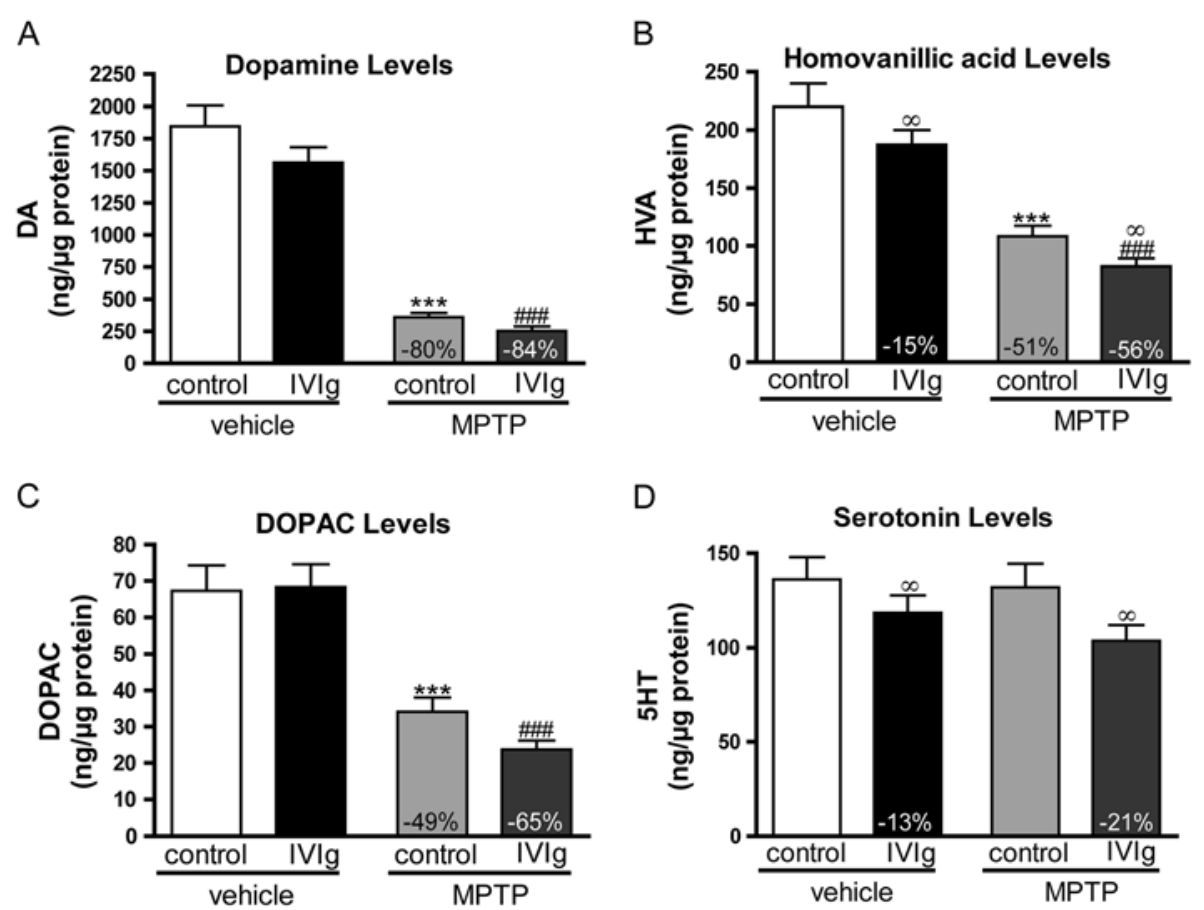

Figure 5 Lack of beneficial effects of intravenous immunoglobulin on depleted levels of dopamine and its metabolites. Catecholamines and indolamine were quantified using HPLC in the striatum of mice. Concentrations of (A) dopamine (DA), (B) homovanillic acid (HVA), and (C) 3,4-dihydroxyphenylacetic acid (DOPAC) remained decreased following MPTP injections and subsequent intravenous immunoglobulin (IVlg) treatment. (D) Concentration of serotonin. (A) to (D) Percentage of control values is indicated for significant variation (vehicle-control or vehicleIVIg, respectively). Two-way analysis of variance (ANOVA) also revealed lower (B) HVA and (D) serotonin levels in IVIg groups. Values represent mean \pm standard error of the mean of 11 to 15 animals per group. Statistical analysis: one-way ANOVA followed by Tukey's multiple comparison

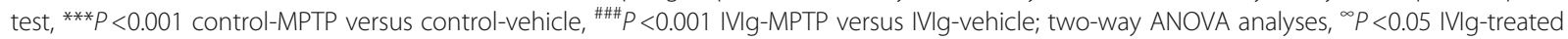
versus control-treated animals. 
A

DA Transporter Levels

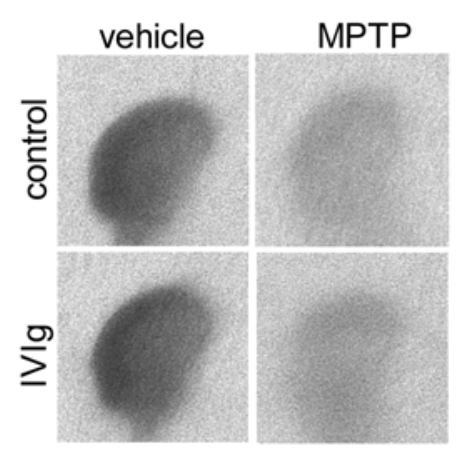

C
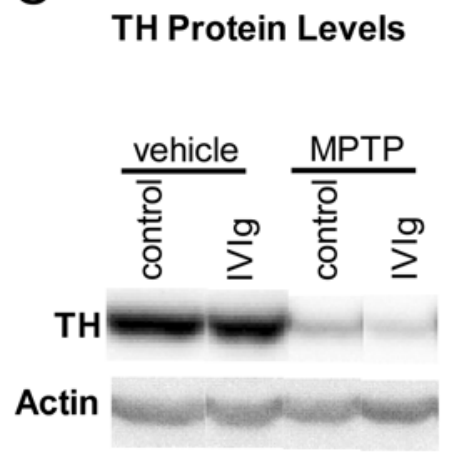

B

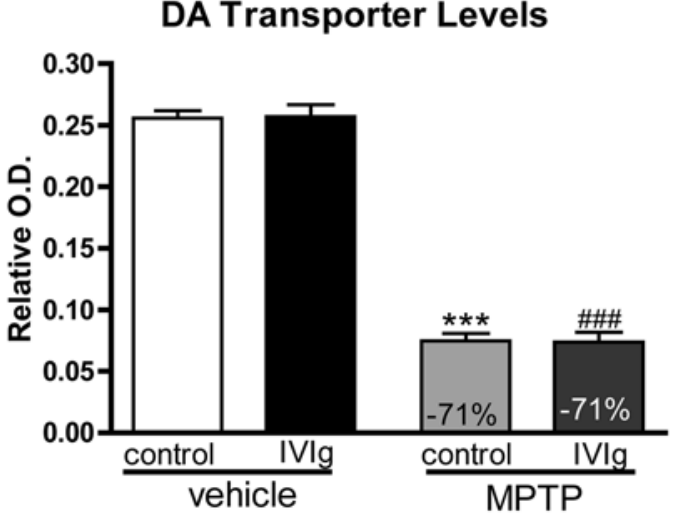

D

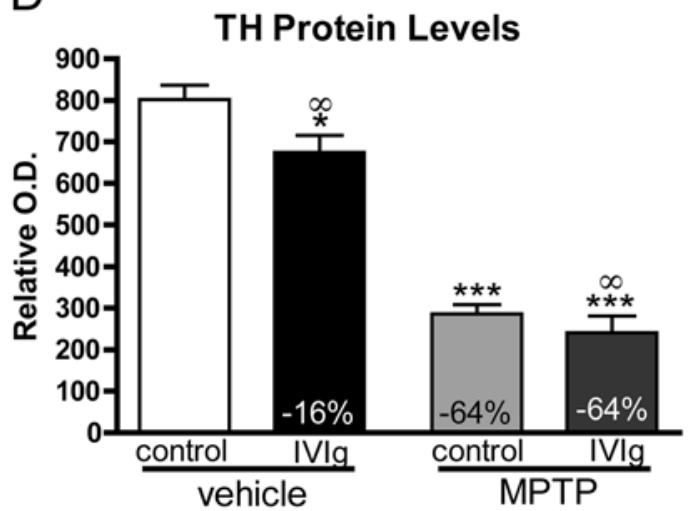

Figure 6 Decreased tyrosine hydroxylase protein and dopamine transporter levels in the mouse striatum following MPTP treatment. ${ }^{125}$ I-RTI-121 specific binding to dopamine transporter (DAT) was measured with receptor binding autoradiography and showed a remarkable decrease following MPTP treatment without any effect of intravenous immunoglobulin (IVlg). (A) Representative autoradiograms and (B) quantification. Statistical analysis: mean \pm standard error of the mean (SEM; $n=11$ to 15/group). One-way analysis of variance (ANOVA) followed by Tukey's multiple comparison test, ${ }^{* *} P<0.001$ control-MPTP versus control-vehicle, ${ }^{\# \# \# ~} P<0.001$ IVlg-MPTP versus IVlg-vehicle. Striatal tyrosine hydroxylase (TH) protein level was also decreased following MPTP intoxication. (C) Representative Western blot of TH in MPTP-mice treated with IVlg or vehicle. (D) Densitometric quantification of the Western blots. Data presented as mean \pm SEM ( $n=11$ to 15/group). Statistical analysis: oneway ANOVA followed by Dunnett's multiple comparison test. ${ }^{* *} P<0.001,{ }^{*} P<0.05$ versus control-vehicle. Besides the downregulating effect of MPTP, a significant IVIg-induced decrease of TH in the striatum of mice was observed in vehicle-treated mice $\left({ }^{*} P<0.05\right.$ vs. control-vehicle) and was further evidenced using two-way ANOVA analyses in both vehicle and MPTP groups ( ${ }^{\infty} P<0.05 \mathrm{IVIg}$ vs. control). Percentage of control values is indicated for significant variation (vehicle-control vs. MPTP-control or vehicle-IVIg vs. MPTP-IVIg, respectively).

cresyl-violet-stained) was also decreased by MPTP treatment (Figure 7B). To verify whether IVIg treatment affected the proportion of TH-positive neurons, we measured the ratio of $\mathrm{TH}$-positive neurons versus total $\mathrm{SNpc}$ cells, as identified with $\mathrm{TH}$ immunohistochemistry and cresyl-violet staining (Figure 7C). Additionally, two-way ANOVA analyses revealed that IVIg treatment led to significant reductions in $\mathrm{TH}$-positive neurons, total number of $\mathrm{SNpc}$ neurons and the ratio of $\mathrm{TH}$-positive versus total $\mathrm{SNpc}$ neurons in mice.

\section{Discussion}

Our data clearly show that IVIg treatment has an impact on various immune parameters in mice, confirming the immunomodulatory action of IVIg in the periphery.
Indeed, systemic administration of IVIg led to the presence of human IgG at the surface of circulating leukocytes, induced a significant decrease in the $\mathrm{CD} 4^{+} / \mathrm{CD} 8^{+}$ T-cell ratio and increased the Treg percentage. In the present study, we have also assessed the state of the brain DAergic system using a combination of validated markers. However, our results suggest that immunomodulating treatment with IVIg did not translate into neurorestoration of the denervated nigrostriatal DAergic pathway after an acute MPTP insult. Our observations rather suggest potentially negative consequences of IVIg treatment on certain components of the DAergic system, as well as on the health status of the treated animals. The vast majority of preclinical studies aiming to test new compounds for PD are tested in animal 

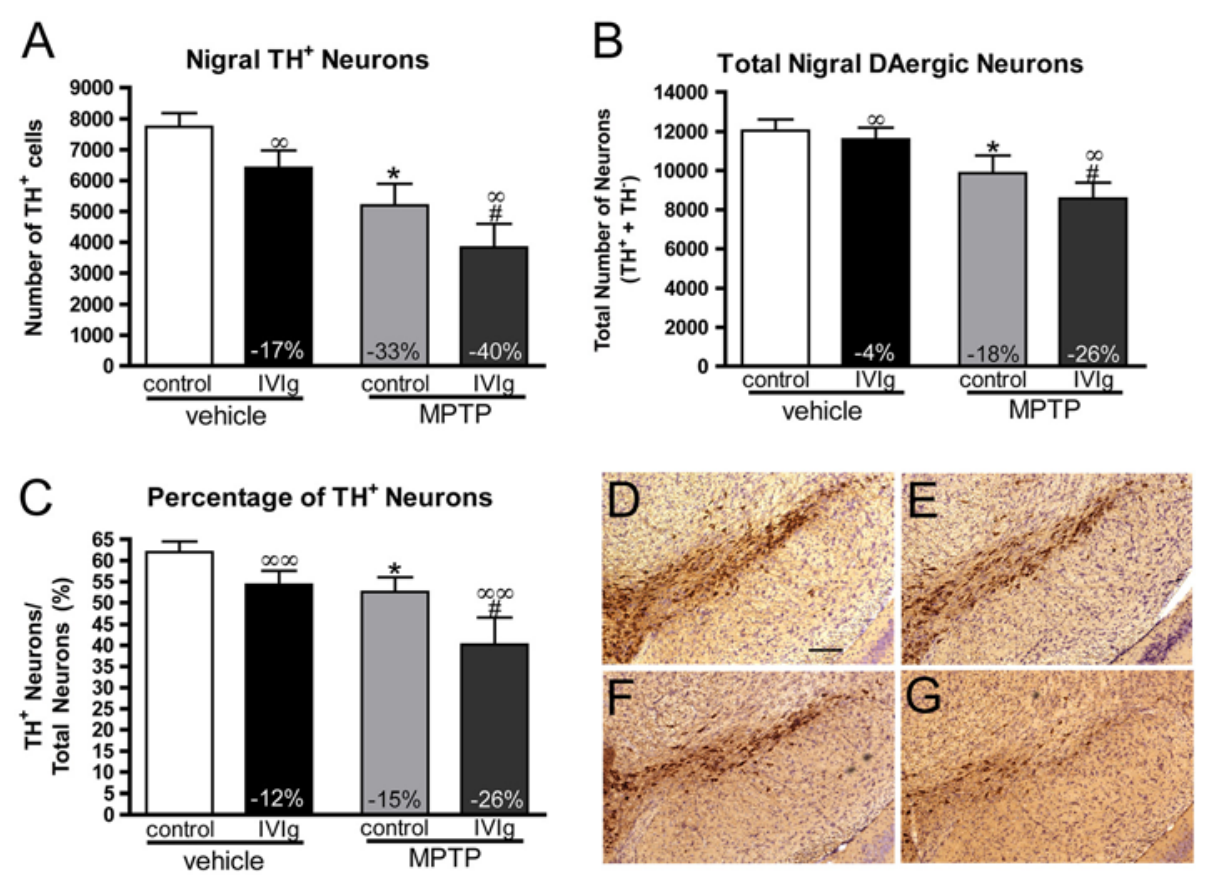

Figure 7 Quantification of nigral tyrosine hydroxylase-positive neurons following MPTP and intravenous immunoglobulin treatment. Stereological counts of (A) tyrosine hydroxylase (TH)-positive dopaminergic (DAergic) neurons and (B) total DAergic neurons of the substantia nigra pars compacta (SNpc) confirming that exposure to MPTP led to a significant nigral neurodegeneration. (C) Ratio of TH-positive versus total SNpc neurons in the SNpc ( $n=12$ to 15 animals per group). (D) to (G) Low power photomicrograph representative of the state of the nigral DAergic system following MPTP and intravenous immunoglobulin (IVlg) treatments. Scale bar: $150 \mu \mathrm{m}$. (D) Vehicle-control, (E) vehicle-IVlg, (F) MPTP-control, (G) MPTP-IVIg. Statistical analysis: one-way analysis of variance (ANOVA) followed by Tukey's multiple comparison test, ${ }^{*} P<0.05$ control-MPTP versus control-vehicle, ${ }^{\#} P<0.05 \mathrm{IVIg}$-MPTP versus IVlg-vehicle. IVlg treatment $(\mathbf{E}),(\mathbf{G})$ resulted in a diminution in the number of THpositive neurons compared with vehicle-treated animals (D), (F), according to two-way ANOVA analyses $\left({ }^{\infty} P<0.05 ;^{\infty \infty} P<0.01 \mathrm{IVIg}\right.$ Vs. control). Percentage of control values is indicated for significant variation (vehicle-control or vehicle-IVlg, respectively).

models prior to the injury (for example, MPTP treatment), thereby probing the neuroprotective properties of the potential therapeutic agents. We opted instead for a neurorestoration study design, in which the injections of IVIg began 20 hours after the last MPTP injection. MPTP-induced neurodegeneration is still ongoing at that time, as DAergic denervation stabilizes approximately 7 days after initial MPTP insult [63-65]. Nevertheless, such post-MPTP treatment paradigm is more compatible with an eventual clinical use of IVIg in human PD, which would occur after the diagnosis, when neurodegeneration processes are already engaged [66].

Treg cell adoptive transfer has been previously reported to protect from MPTP-induced nigrostriatal denervation [57-59] in acute MPTP mouse models. In these studies, the amount of Tregs needed to achieve neurorestoration using adoptive transfer ranged between $0.5 \times 10^{6}$ and $3.5 \times 10^{6}$ injected into the tail vein 12 hours following the last MPTP injection [57-59]. We also observed a rise in Treg percentage among the $\mathrm{CD} 4^{+}$ population, reaching up to $9 \%$ in the spleen of IVIgvehicle mice, after a 14-day treatment. However, this increase in Tregs following IVIg administration did not reach the 16 to $20 \% \mathrm{CD}^{+}$Treg proportion previously reported [53,54]. Nevertheless, despite the significant rise in peripheral Tregs, IVIg treatment did not translate into measurable neurorestorative effects. The lack of beneficial effects could be explained by the fact that the rise in Tregs following the initiation of IVIg treatment might have been too slow to allow a sufficient exposure to Tregs to produce any benefits. We also observed a significant increase of Treg percentage after MPTP administration with no additive effects of IVIg. This is in accordance with Rosenkranz and colleagues, who reported a higher suppressive activity of Tregs in PD and AD patients and an increased Treg number associated with aging [67]. Finally, Ramakrishna and colleagues associated the longterm regulation of CNS inflammatory responses to the induction of $\mathrm{iCOS}^{+} \mathrm{CD}^{+}{ }^{+} \mathrm{T}$ cells [54], which were left unchanged after the present IVIg treatment. The absence of neurorestorative effects of IVIg could thus also be explained by the lack of expansion of the $\mathrm{iCOS}^{+} \mathrm{CD} 4^{+} \mathrm{T}$ cells or the Treg population in the MPTP-treated groups. 
Injections of IVIg resulted in a mild but significant decrease in the $\mathrm{CD} 4^{+} / \mathrm{CD}^{+} \mathrm{T}$-cell ratio. Such decreases are also observed in IVIg-treated patients [68], suggesting it may be a clinically relevant index of IVIg efficacy. Interestingly, a significant decrease in $\mathrm{CD} 4^{+} / \mathrm{CD} 8^{+}$ratio is observed in PD patients as well [69-71], possibly accounted for by an increased susceptibility to apoptosis observed in $\mathrm{CD}^{+} \mathrm{T}$ cells, consequent of Fas overexpression [72]. IVIg has been reported to modulate the level of expression of Fas and FasL and to inhibit FasLdependent apoptosis, in both in vivo and in vitro studies [34,73-75]. This action of IVIg on the Fas/FasL pathway could have been translated into neurorestoration. However, while being consistent with an immunoregulatory action, the effect of IVIg on the $\mathrm{CD} 4^{+} / \mathrm{CD}^{+}{ }^{+} \mathrm{T}$-cell ratio was not associated with beneficial post-MPTP outcomes on various DAergic markers.

The lack of efficacy of IVIg may also reflect the poor CNS access owing to the presence of the blood-brain barrier. However, our data rather suggest that IVIg displayed significant central bioavailability after systemic administration. Indeed, a fraction of intraperitoneally administered IVIg was detected in the striatum of treated mice using a specific ELISA, consistent with a previous report where peripherally administered IVIg was also detected in APP/PS1 mouse brain using immunohistochemistry [76]. A number of studies have reported data consistent with the penetration of a fraction of systemically administered antibodies into brain tissues leading to central therapeutic effect $[38,77,78]$. Interaction between $F_{c}$ gamma receptor $(\mathrm{Fc} \gamma \mathrm{R})$ and immunoglobulins is essential for the initiation of cellular and humoral responses. In the CNS, Fc $\gamma \mathrm{R}$ are expressed on endothelial cells, neurons, microglia, oligodendrocytes and astrocytes (as reviewed in [79]) and the IVIg migration to critical regions of the brain, such as the striatum and $\mathrm{SNpc}$ in PD, might act as a central immunomodulating agent. A previous report showed that approximately $30 \%$ of pigmented SNpc neurons were IgG-positive [80] in PD patients but not in controls. This suggests that IgG can access the brain during the course of the disease. However, we found no increase in striatal IgG content in MPTP-treated animals. The amount of human IgG detected in the brain of treated mice suggests that low central bioavailability is unlikely to be the sole reason for the lack of efficacy of IVIg in restoring the DAergic pathways.

After systemic injection, MPTP produces a reproducible lesion of the nigrostriatal DAergic pathway by causing oxidative stress, mitochondrial damage and neuronal cell death, as in idiopathic PD. Validation of disease-modifying treatments before clinical trial initiation is therefore often performed in MPTP-treated rodent models $[81,82]$. However, these models are not without important limitations [83]. First, the MPTP model used here does not generate a massive degeneration ( -30 to $40 \%$ of $\mathrm{TH}$-positive cells), which is required for clinically detectable motor symptoms in humans $(-50$ to $60 \%)[84,85]$. This explains, at least in part, why motor symptoms in the MPTP mouse model are insufficiently reliable for systematic assessment [83,86-89] and were not evaluated here after IVIg treatment. To investigate the symptomatic effects of IVIg, the use of the more expensive MPTP monkey model should be considered instead [83,90]. Second, the acute mouse MPTP model does not replicate $\alpha$-synucleinopathy or Lewy bodies, which are pathognomonic of PD [91-93]. The use of other models such as the chronic infusion MPTP models or transgenic mice overexpressing human $\alpha$-syn might be helpful for these purposes [81,93-95]. Third, the response of a mouse model to human IVIg may differ from humans. Indeed, the absence of positive outcome in our study might be the result of inadequate interactions between human IgG and mouse Fc $\gamma R$, a hypothesis only testable with the use of mouse IgG. However, given that over 2,500 mice would have been required to generate the $\sim 5 \mathrm{~g}$ IgG used in this study, murine IgG is scarcely used in preclinical investigations. In a passive model of idiopathic thrombocytopenic purpura, human IVIg and purified mouse IgG shared the same kinetics to restore platelet counts, thus validating the use of human IVIg to study human therapy in mouse models [96]. Since monomeric human IVIg is well tolerated in mice, mouse models of numerous diseases are now routinely used to investigate its efficacy as well as its mechanisms of action $[35,53,97,98]$.

The unexpected deleterious effect of IVIg on TH expression is an intriguing observation that is particularly challenging to explain. On the one hand, a plethora of compounds such as nicotine, cannabinoid agonists and progesterone receptor isoforms [99-101] have been shown to modulate $\mathrm{TH}$ expression without obvious harmful effects on the DAergic system. Similarly, our data suggest that IVIg regulates TH expression at the protein or RNA levels. On the other hand, the observed decrease in striatal $\mathrm{TH}$ protein levels associated with a trend toward decreased catecholamines, serotonin, nigral $\mathrm{TH}$-positive and total neurons can also be interpreted as a deleterious effect of IVIg on the murine DAergic system. Although acute MPTP administration does not lead to $\alpha$-syn-positive nigral inclusions [91-93], $\alpha$-syn-deficient transgenic mouse models are more resistant to MPTP, suggesting a possible implication of $\alpha$-syn in the MPTP toxicity [102-106]. Increased autoantibodies to $\alpha$-syn are present in the sera of PD patients $[107,108]$, and stereotactic injection of human IgG purified from the sera of PD patients into mice SNpc produces a $\mathrm{Fc} \gamma \mathrm{R}$ dependent microglial activation and a $40 \% \mathrm{TH}$-positive 
cell loss in the SNpc [109]. Since natural anti- $\alpha$-syn antibodies in IVIg preparations have been recently identified [40], it is tempting to speculate that IVIg could have modulated the nigrostriatal toxicity of MPTP by binding to $\alpha$-syn.

\section{Conclusion}

Despite the fact that current knowledge of IVIg mechanisms of action holds promising characteristics for the treatment of PD, our results do not provide evidence of a neurorestorative effect of IVIg treatment on the nigrostriatal system of the MPTP-treated mouse. Our data on the general health status, DAergic cell count, $\mathrm{TH}$ protein levels and HVA striatal concentrations all suggest that IVIg not only failed to generate beneficial effects, but had a slight detrimental impact on the DAergic system. Such possible harmful consequences flag the need to proceed with caution before initiating clinical trials in PD patients.

\section{Abbreviations \\ AD: Alzheimer disease; ANOVA: analysis of variance; BSA: bovine serum albumin; CD: cluster of differentiation; CNS: central nervous system; DA: dopamine; DAergic: dopaminergic; DAT: dopamine transporter; DOPAC: 3,4-dihydroxyphenylacetic acid; ELISA: enzyme-linked immunosorbent assay; FasL: Fas ligand; FcyR: Fc gamma receptor; FITC: fluorescein isothiocyanate; HPLC: high-performance liquid chromatography; HVA: homovanillic acid; IFN: interferon; IL: interleukin; I-RTI- 121: 3ß-(4-125/-iodophenyl) tropane-2-carboxylic acid isopropylester; IVlg: intravenous immunoglobulin; MPTP: 1-methyl-4-phenyl-1,2,3,6- tetrahydropyridine; PBS: phosphate-buffered saline; PD: Parkinson's disease; PE: R-phycoerythrin; TGFb: transforming growth factor-beta; TH: tyrosine hydroxylase; TNF: tumor necrosis factor; Treg: regulatory T cell; \\ SNpc: substantia nigra pars compacta; a-syn: a-synuclein.}

\section{Competing interests}

FCa and RB have received funding from Grifols for other research projects on IVIg. The remaining authors declare that they have no competing interests.

\section{Authors' contributions}

IS-A participated in the design of the experiments, performed the animal studies and most of the postmortem analyses, analyzed the data and wrote the manuscript. MB participated in the design of the experiments and animal studies, executed the HPLC analyses and revised the manuscript. IP performed the flow cytometry and ELISPOT experiments. JD-O participated in animal studies, carried out the stereological quantification and revised the manuscript. FCi provided scientific input and revised the manuscript. RB provided resources for flow cytometry analyses and revised the manuscript. FCa conceived and designed the study, analyzed the data and wrote the manuscript. All authors read and approved the final version of the manuscript.

\section{Acknowledgements}

This work was supported by the Canadian Institutes of Health Research (CIHR; grant ISO-102447) and the Héma-Québec foundation. IS-A was supported by an Industrial Innovation PhD scholarship from CRSNG/FQRNT/ Héma-Quebec. MB and JD-O were supported by CIHR scholarships. FCa and FCi are supported by salary awards from the Fonds de la recherche en santé du Québec.

\section{Author details}

${ }^{1}$ Centre de Recherche du CHUL (CHUQ), Axe Neurosciences, T2-05, 2705, boulevard Laurier, Québec, QC, Canada G1V 4G2. 'Faculté de Pharmacie, Université Laval, Québec, QC, Canada G1V OA6. ${ }^{3}$ Département de Recherche et Développement, Héma-Québec, Québec, QC, Canada GIV 5C3.
${ }^{4}$ Département de Psychiatrie \& Neurosciences, Faculté de Médecine, Université Laval, Québec, QC, CanadaG1V OA6.

Received: 25 May 2012 Accepted: 16 September 2012 Published: 9 October 2012

\section{References}

1. Lofrumento DD, Saponaro C, Cianciulli A, De Nuccio F, Mitolo V, Nicolardi G, Panaro MA: MPTP-induced neuroinflammation increases the expression of pro-inflammatory cytokines and their receptors in mouse brain. Neuroimmunomodulation 2011, 18:79-88.

2. Vroon A, Drukarch B, Bol JGJM, Cras P, Brevé JJP, Allan SM, Relton JK, Hoogland PVJM, Van Dam AM: Neuroinflammation in Parkinson's patients and MPTP-treated mice is not restricted to the nigrostriatal system: microgliosis and differential expression of interleukin-1 receptors in the olfactory bulb. Exp Gerontol 2007, 42:762-771.

3. Boka G, Anglade P, Wallach D, Javoy-Agid F, Agid Y, Hirsch EC: Immunocytochemical analysis of tumor necrosis factor and its receptors in Parkinson's disease. Neurosci Lett 1994, 172:151-154.

4. Mogi M, Harada M, Kondo T, Narabayashi H, Riederer P, Nagatsu T: Transforming growth factor-beta 1 levels are elevated in the striatum and in ventricular cerebrospinal fluid in Parkinson's disease. Neurosci Lett 1995, 193:129-132.

5. Mogi M, Harada M, Riederer P, Narabayashi H, Fujita K, Nagatsu T: Tumor necrosis factor-alpha (TNF-a) increases both in the brain and in the cerebrospinal fluid from parkinsonian patients. Neurosci Lett 1994, 165:208-210.

6. Mogi M, Kondo T, Mizuno $\mathrm{Y}$, Nagatsu T: p53 protein, interferon-gamma, and NF-Kb levels are elevated in the parkinsonian brain. Neurosci Lett 2007, 414:94-97.

7. Scalzo P, Kummer A, Cardoso F, Teixeira AL: Serum levels of interleukin-6 are elevated in patients with Parkinson's disease and correlate with physical performance. Neurosci Lett 2010, 468:56-58.

8. Scalzo P, Kummer A, Cardoso F, Teixeira AL: Increased serum levels of soluble tumor necrosis factor-alpha receptor-1 in patients with Parkinson's disease. J Neuroimmunol 2009, 216:122-125.

9. Stypula G, Kunert-Radek J, Stepien H, Zylinska K, Pawlikowski M: Evaluation of interleukins, ACTH, cortisol and prolactin concentrations in the blood of patients with parkinson's disease. Neuroimmunomodulation 1996, 3:131-134.

10. Dobbs RJ, Charlett A, Purkiss AG, Dobbs SM, Weller C, Peterson DW: Association of circulating TNF-alpha and IL-6 with ageing and parkinsonism. Acta Neurol Scand 1999, 100:34-41.

11. Varani K, Vincenzi F, Tosi A, Gessi S, Casetta I, Granieri G, Fazio P, Leung E, MacLennan S, Granieri E, Borea PA: A2A adenosine receptor overexpression and functionality, as well as TNF-alpha levels, correlate with motor symptoms in Parkinson's disease. FASEB J 2010, 24:587-598.

12. Nicoletti A, Fagone P, Donzuso G, Mangano K, Dibilio V, Caponnetto S, Bendtzen K, Zappia M, Nicoletti F: Parkinson's disease is associated with increased serum levels of macrophage migration inhibitory factor. Cytokine 2011, 55:165-167.

13. Hofmann KW, Schuh AFS, Saute J, Townsend R, Fricke D, Leke R, Souza DO, Portela LV, Chaves MLF, Rieder CRM: Interleukin-6 serum levels in patients with Parkinson's disease. Neurochem Res 2009, 34:1401-1404.

14. Brochard V, Combadière B, Prigent A, Laouar Y, Perrin A, Beray-Berthat V, Bonduelle O, Alvarez-Fischer D, Callebert J, Launay J-M, Duyckaerts C, Flavell $\mathrm{RA}$, Hirsch EC, Hunot S: Infiltration of $\mathrm{CD}^{+}$lymphocytes into the brain contributes to neurodegeneration in a mouse model of Parkinson disease. J Clin Invest 2008, 119:182-192.

15. Dodel R, Neff F, Noelker C, Pul R, Du Y, Bacher M, Oertel W: Intravenous immunoglobulins as a treatment for Alzheimer's disease: rationale and current evidence. Drugs 2010, 70:513-528.

16. Stein MR, Nelson RP, Church JA, Wasserman RL, Borte M, Vermylen C, Bichler J: Safety and efficacy of Privigen, a novel $10 \%$ liquid immunoglobulin preparation for intravenous use, in patients with primary immunodeficiencies. J Clin Immunol 2009, 29:137-144.

17. Ballow M, Berger M, Bonilla FA, Buckley RH, Cunningham-Rundles $\mathrm{CH}$, Fireman P, Kaliner M, Ochs HD, Skoda-Smith S, Sweetser MT, Taki H, Lathia C: Pharmacokinetics and tolerability of a new intravenous immunoglobulin preparation, IGIV-C, 10\% (Gamunex, 10\%). Vox Sang 2003, 84:202-210. 
18. Roifman CM, Schroeder H, Berger M, Sorensen R, Ballow M, Buckley RH, Gewurz A, Korenblat P, Sussman G, Lemm G: Comparison of the efficacy of IGIV-C, 10\% (caprylate/chromatography) and IGIV-SD, 10\% as replacement therapy in primary immune deficiency. Int Immunopharmacol 2003, 3:1325-1333.

19. Lebing W, Remington KM, Schreiner C, Paul HI: Properties of a new intravenous immunoglobulin (IGIV-C, 10\%) produced by virus inactivation with caprylate and column chromatography. Vox Sang 2003, 84:193-201.

20. Nimmerjahn F, Ravetch JV: Anti-inflammatory actions of intravenous immunoglobulin. Annu Rev Immunol 2008, 26:513-533.

21. Lehmann HC, Hartung HP: Plasma exchange and intravenous immunoglobulins: mechanism of action in immune-mediated neuropathies. J Neuroimmunol 2011, 231:61-69.

22. Tackenberg B, Nimmerjahn F, Lunemann JD: Mechanisms of IVIG efficacy in chronic inflammatory demyelinating polyneuropathy. J Clin Immunol 2010, 30(Suppl 1):S65-S69.

23. Pigard N, Elovaara I, Kuusisto H, Paalavuo R, Dastidar P, Zimmermann K, Schwarz HP, Reipert B: Therapeutic activities of intravenous immunoglobulins in multiple sclerosis involve modulation of chemokine expression. J Neuroimmunol 2009, 209:114-120.

24. Kaveri SV, Maddur MS, Hegde P, Lacroix-Desmazes S, Bayry J: Intravenous immunoglobulins in immunodeficiencies: more than mere replacement therapy. Clin Exp Immunol 2011, 164:2-5.

25. Negi VS, Elluru S, Siberil S, Graff-Dubois S, Mouthon L, Kazatchkine MD, Lacroix-Desmazes S, Bayry J, Kaveri SV: Intravenous immunoglobulin: an update on the clinical use and mechanisms of action. J Clin Immunol 2007, 27:233-245.

26. Siberil S, Elluru S, Graff-Dubois S, Negi VS, Delignat S, Mouthon L, LacroixDesmazes S, Kazatchkine MD, Bayary J, Kaveri SV: Intravenous immunoglobulins in autoimmune and inflammatory diseases: a mechanistic perspective. Ann N Y Acad Sci 2007, 1110:497-506.

27. Bayary J, Dasgupta S, Misra N, Ephrem A, Van H, Jean-Paul D, Delignat S, Hassan G, Caligiuri G, Nicoletti A, Lacroix-Desmazes S, Kazatchkine MD, Kaveri S: Intravenous immunoglobulin in autoimmune disorders: an insight into the immunoregulatory mechanisms. Int Immunopharmacol 2006, 6:528-534

28. Vani J, Elluru S, Negi V-S, Lacroix-Desmazes S, Kazatchkine MD, Bayary J, Kaveri SV: Role of natural antibodies in immune homeostasis: IVIg perspective. Autoimmun Rev 2008, 7:440-444.

29. Creange A, Belec L, Clair B, Degos JD, Raphael JC, Gherardi RK: Circulating transforming growth factor beta 1 (TGF- $\beta 1$ ) in Guillain-Barre syndrome: decreased concentrations in the early course and increase with motor function. J Neurol Neurosurg Psychiatry 1998, 64:162-165.

30. Keskin DB, Stern JNH, Fridkis-Hareli M, Razzaque A: Cytokine profiles in pemphigus vulgaris patients treated with intravenous immunoglobulins as compared to conventional immunosuppressive therapy. Cytokine 2008, 41:315-321.

31. Stangel M, Compston A: Polyclonal immunoglobulins (IVIg) modulate nitric oxide production and microglial functions in vitro via Fc receptors. J Neuroimmunol 2001, 112:63-71.

32. Issekutz AC, Rowter D, MacMillan HF: Intravenous immunoglobulin G (IVIG) inhibits IL-1- and TNF-alpha-dependent, but not chemotacticfactor-stimulated, neutrophil transendothelial migration. Clin Immunol 2011, 141:187-196

33. Lapointe BM: IVlg therapy in brain inflammation: etiology-dependent differential effects on leucocyte recruitment. Brain 2004, 127:2649-2656

34. Reipert BM, Stellamor MT, Poell M, Ilas J, Sasgary M, Reipert S, Zimmermann K, Ehrlich H, Schwarz HP: Variation of anti-Fas antibodies in different lots of intravenous immunoglobulin. Vox Sang 2008, 94:334-341.

35. Puli L, Pomeshchik Y, Olas K, Malm T, Koistinaho J, Tanila H: Effects of human intravenous immunoglobulin on amyloid pathology and neuroinflammation in a mouse model of Alzheimer's disease. J Neuroinflammation 2012, 9:105.

36. Vekrellis K, Xilouri M, Emmanouilidou E, Rideout HJ, Stefanis L: Pathological roles of alpha-synuclein in neurological disorders. Lancet Neurol 2011, 10:1015-1025.

37. Yasuda $T$, Mochizuki $H$ : The regulatory role of alpha-synuclein and parkin in neuronal cell apoptosis; possible implications for the pathogenesis of Parkinson's disease. Apoptosis 2010, 15:1312-1321.
38. Masliah E, Rockenstein E, Mante M, Crews L, Spencer B, Adame A, Patrick C, Trejo M, Ubhi K, Rohn T, Mueller-Steiner S, Seubert P, Barbour R, McConlogue L, Buttini M, Games D, Schenk D: Passive immunization reduces behavioral and neuropathological deficits in an alpha-synuclein transgenic model of lewy body disease. PLoS One 2011, 6:e19338.

39. Masliah E, Rockenstein E, Adame A, Alford M, Crews L, Hashimoto M Seubert P, Lee M, Goldstein J, Chilcote T, Games D, Schenk D: Effects of alpha-synuclein immunization in a mouse model of Parkinson's disease. Neuron 2005, 46:857-868

40. Patrias LM, Klaver AC, Coffey MP, Loeffler DA: Specific antibodies to soluble alpha-synuclein conformations in intravenous immunoglobulin preparations. Clin Exp Immunol 2010, 161:527-535.

41. Obeso JA, Rodriguez-Oroz MC, Goetz CG, Marin C, Kordower JH, Rodriguez M, Hirsch EC, Farrer M, Schapira AHV, Halliday G: Missing pieces in the Parkinson's disease puzzle. Nat Med 2010, 16:653-661.

42. Nomoto M: Clinical pharmacology and neuroprotection in Parkinson's disease. Parkinsonism Relat Disord 2003, 9:55-58.

43. Jackson-Lewis V, Przedborski S: Protocol for the MPTP mouse model of Parkinson's disease. Nat Protoc 2007, 2:141-151.

44. Yokoyama H, Kuroiwa H, Kasahara J, Araki T: Neuropharmacological approach against MPTP (1-methyl-4-phenyl-1,2,3,6-tetrahydropyridine)induced mouse model of Parkinson's disease. Acta Neurobiol Exp 2011, 71:269-280.

45. Calon F, Lavertu N, Lemieux AM, Morissette M, Goulet M, Grondin R, Blanchet PJ, Bédard PJ, Di Paolo T: Effect of MPTP-induced denervation on basal ganglia $\mathrm{GABA}(\mathrm{B})$ receptors: correlation with dopamine concentrations and dopamine transporter. Synapse 2001, 40:225-234.

46. Relkin NR, Szabo P, Adamiak B, Burgut T, Monthe C, Lent RW, Younkin S, Younkin L, Schiff R, Weksler ME: 18-Month study of intravenous immunoglobulin for treatment of mild Alzheimer disease. Neurobiol Aging 2008, 30:1728-1736.

47. Tremblay C, Pilote M, Phivilay A, Emond V, Bennett DA, Calon F: Biochemical characterization of Abeta and tau pathologies in mild cognitive impairment and Alzheimer's disease. J Alzheimers Dis 2007, 12:377-390

48. Bousquet M, St-Amour I, Vandal M, Julien P, Cicchetti F, Calon F: High-fat diet exacerbates MPTP-induced dopaminergic degeneration in mice. Neurobiol Dis 2012, 45:529-538.

49. Bousquet M, Saint-Pierre M, Julien C, Salem N, Cicchetti F, Calon F: Beneficial effects of dietary omega-3 polyunsaturated fatty acid on toxin-induced neuronal degeneration in an animal model of Parkinson's disease. FASEB J 2008, 22:1213-1225.

50. Drouin-Ouellet J, Gibrat C, Bousquet M, Calon F, Kriz J, Cicchetti F: The role of the MYD88-dependent pathway in MPTP-induced brain dopaminergic degeneration. J Neuroinflammation 2011, 8:137.

51. Olivito B, Taddio A, Simonini G, Massai C, Ciullini S, Gambineri E, de Martino M, Azzari C, Cimaz R: Defective FOXP3 expression in patients with acute Kawasaki disease and restoration by intravenous immunoglobulin therapy. Clin Exp Rheumatol 2010, 28:93-97.

52. Tsurikisawa N, Saito H, Oshikata C, Tsuburai T, Akiyama K: High-dose intravenous immunoglobulin treatment increases regulatory $\mathrm{T}$ cells in patients with eosinophilic granulomatosis with polyangiitis. J Rheumatol 2012, 39:1019-1025

53. Ephrem A, Chamat S, Miquel C, Fisson S, Mouthon L, Caligiuri G, Delignat S, Elluru S, Bayry J, Lacroix-Desmazes S, Cohen JL, Salomon BL, Kazatchkine $\mathrm{MD}$, Kaveri SV, Misra N: Expansion of $\mathrm{CD} 4^{+} \mathrm{CD} 25^{+}$regulatory T cells by intravenous immunoglobulin: a critical factor in controlling experimental autoimmune encephalomyelitis. Blood 2008, 111:715-722.

54. Ramakrishna C, Newo ANS, Shen Y-W, Cantin E: Passively administered pooled human immunoglobulins exert IL-10 dependent antiinflammatory effects that protect against fatal HSV encephalitis. PLOS Pathog 2011, 7:e1002071

55. Sakaguchi S, Miyara M, Costantino CM, Hafler DA: FoxP3(+) regulatory T cells in the human immune system. Nat Rev Immunol 2010, 10:490-500.

56. Poojary KV, Kong Y-M, Farrar MA: Control of Th2-mediated inflammation by regulatory T cells. Am J Pathol 2010, 177:525-531.

57. Reynolds AD, Stone DK, Hutter JAL, Benner EJ, Mosley RL, Gendelman HE: Regulatory $\mathrm{T}$ cells attenuate Th17 cell-mediated nigrostriatal dopaminergic neurodegeneration in a model of Parkinson's disease. $\mathrm{J}$ Immunol 2010, 184:2261-2271. 
58. Reynolds AD, Banerjee R, Liu J, Gendelman HE, Mosley RL: Neuroprotective activities of $\mathrm{CD} 4{ }^{+} \mathrm{CD} 25^{+}$regulatory $T$ cells in an animal model of Parkinson's disease. J Leukoc Biol 2007, 82:1083-1094.

59. Chi Y, Fan $Y$, He L, Liu W, Wen X, Zhou S, Wang X, Zhang C, Kong H, Sonoda L, Tripathi P, Li CJ, Yu MS, Su C, Hu G: Novel role of aquaporin-4 in $\mathrm{CD}^{+}, \mathrm{CD} 25^{+} \mathrm{T}$ regulatory cell development and severity of Parkinson's disease. Aging Cell 2011, 10:368-382.

60. Starke C, Frey S, Wellmann U, Urbonaviciute V, Herrmann M, Amann K, Schett G, Winkler T, Voll RE: High frequency of autoantibody-secreting cells and long-lived plasma cells within inflamed kidneys of NZB/W F1 lupus mice. Eur J Immunol 2011, 41:2107-2112.

61. Bontscho J, Schreiber A, Manz RA, Schneider W, Luft FC, Kettritz R: Myeloperoxidase-specific plasma cell depletion by Bortezomib protects from anti-neutrophil cytoplasmic autoantibodies-induced glomerulonephritis. J Am Soc Nephrol 2011, 22:336-348.

62. Daubner SC, Le T, Wang S: Tyrosine hydroxylase and regulation of dopamine synthesis. Arch Biochem Biophys 2011, 508:1-12

63. Jakowec MW, Nixon K, Hogg E, McNeill T, Petzinger GM: Tyrosine hydroxylase and dopamine transporter expression following 1-methyl-4phenyl-1,2,3,6-tetrahydropyridine-induced neurodegeneration of the mouse nigrostriatal pathway. J Neurosci Res 2004, 76:539-550.

64. Jackson-Lewis $V$, Jakowec M, Burke RE, Przedborski S: Time course and morphology of dopaminergic neuronal death caused by the neurotoxin 1-methyl-4-phenyl-1,2,3,6-tetrahydropyridine. Neurodegeneration 1995, 4:257-269.

65. Bezard E, Dovero S, Bioulac B, Gross C: Effects of different schedules of MPTP administration on dopaminergic neurodegeneration in mice. Exp Neurol 1997, 148:288-292.

66. Bezard E: A call for clinically driven experimental design in assessing neuroprotection in experimental Parkinsonism. Behav Pharmacol 2006, 17:379-382.

67. Rosenkranz D, Weyer S, Tolosa E, Gaenslen A, Berg D, Leyhe T, Gasser T, Stoltze L: Higher frequency of regulatory $T$ cells in the elderly and increased suppressive activity in neurodegeneration. J Neuroimmunol 2007, 188:117-127.

68. Aukrust P, Muller F, Nordoy I, Haug CJ, Froland SS: Modulation of lymphocyte and monocyte activity after intravenous immunoglobulin administration in vivo. Clin Exp Immunol 1997, 107:50-56.

69. Baba T, Ishizu A, Iwasaki S, Suzuki A, Tomaru U, Ikeda H, Yoshiki T, Kasahara $\mathrm{M}: \mathrm{CD}^{+} / \mathrm{CD}^{+}$macrophages infiltrating at inflammatory sites: a population of monocytes/macrophages with a cytotoxic phenotype. Blood 2006, 107:2004-2012

70. Bas J, Calopa M, Mestre M, MD G, Cutillas B, Ambrosio S, Buendia E: Lymphocyte populations in Parkinson's disease and in rat models of parkinsonism. J Neuroimmunol 2001, 113:146-152.

71. Hisanaga $K$, Asagi M, Itoyama $Y$, Iwasaki $Y$ : Increase in peripheral CD4 bright + CD8 dull + T cells in Parkinson disease. Arch Neurol 2001, 58:1580-1583

72. Calopa M, Bas J, Callen A, Mestre M: Apoptosis of peripheral blood lymphocytes in Parkinson patients. Neurobiol Dis 2010, 38:1-7.

73. Janke AD, Giuliani F, Yong WW: IVlg attenuates T cell-mediated killing of human neurons. J Neuroimmunol 2006, 177:181-188.

74. Ito K, Hara H, Okada T, Shimojima H, Suzuki H: Toxic epidermal necrolysis treated with low-dose intravenous immunoglobulin: immunohistochemical study of Fas and Fas-ligand expression. Clin Exp Dermatol 2004, 29:679-680

75. Artac H, Kara R, Reisli I: In vivo modulation of the expressions of Fas and CD25 by intravenous immunoglobulin in common variable immunodeficiency. Clin Exp Med 2009, 10:27-31.

76. Magga J, Puli L, Pihlaja R, Kanninen K, Neulamaa S, Malm T, Hartig W Grosche J, Goldsteins G, Tanila H, Koistinaho J, Koistinaho M: Human intravenous immunoglobulin provides protection against Abeta toxicity by multiple mechanisms in a mouse model of Alzheimer's disease. J Neuroinflammation 2010, 7:90

77. Kitazawa M, Cheng D, Tsukamoto MR, Koike MA, Wes PD, Vasilevko V, Cribbs DH, LaFerla FM: Blocking IL-1 signaling rescues cognition, attenuates Tau pathology, and restores neuronal beta-catenin pathway function in an Alzheimer's disease model. J Immunol 2011, 187:6549.

78. Tan J, Town T, Crawford F, Mori T, Delledonne A, Crescentini R, Obregon D, Flavell RA, Mullan MJ: Role of CD40 ligand in amyloidosis in transgenic Alzheimer's mice. Nat Neurosci 2002, 5:1288-1293.
79. Okun E, Mattson M, Arumugam T: Involvement of Fc receptors in disorders of the central nervous system. Neuromol Med 2010, 12:164-178

80. Orr CF: A possible role for humoral immunity in the pathogenesis of Parkinson's disease. Brain 2005, 128:2665-2674.

81. Bezard E, Przedborski S: A tale on animal models of Parkinson's disease. Mov Disord 2011, 26:993-1002.

82. Duty S, Jenner P: Animal models of Parkinson's disease: a source of novel treatments and clues to the cause of the disease. Br J Pharmacol 2011, 164:1357-1391.

83. Meissner W, Hill MP, Tison F, Gross CE, Bezard E: Neuroprotective strategies for Parkinson's disease: conceptual limits of animal models and clinical trials. Trends Pharmacol Sci 2004, 25:249-253.

84. Riederer $P$, Wuketich S: Time course of nigrostriatal degeneration in parkinson's disease. A detailed study of influential factors in human brain amine analysis. J Neural Transm 1976, 38:277-301.

85. Bernheimer H, Birkmayer W, Hornykiewicz O, Jellinger K, Seitelberger F: Brain dopamine and the syndromes of Parkinson and Huntington. Clinical, morphological and neurochemical correlations. J Neurol Sci 1973, 20:415-455.

86. Meredith GE, Kang UJ: Behavioral models of Parkinson's disease in rodents: a new look at an old problem. Mov Disord 2006, 21:1595-1606.

87. Chagniel L, Robitaille C, Lacharité-Mueller C, Bureau G, Cyr M: Partial dopamine depletion in MPTP-treated mice differentially altered motor skill learning and action control. Behav Brain Res 2012, 228:9-15.

88. Hutter-Saunders JAL, Gendelman HE, Mosley RL: Murine motor and behavior functional evaluations for acute 1-methyl-4-phenyl-1,2,3,6 tetrahydropyridine (MPTP) intoxication. J Neuroimmune Pharmacol 2011, 7:279-288.

89. Rousselet E, Joubert C, Callebert J, Parain K, Tremblay L, Orieux G, Launay J-M, Cohen-Salmon C, Hirsch EC: Behavioral changes are not directly related to striatal monoamine levels, number of nigral neurons, or dose of parkinsonian toxin MPTP in mice. Neurobiol Dis 2003, $14: 218-228$

90. Jenner P: The contribution of the MPTP-treated primate model to the development of new treatment strategies for Parkinson's disease. Parkinsonism Relat Disord 2003, 9:131-137.

91. Shimoji M, Zhang L, Mandir A, Dawson V, Dawson T: Absence of inclusion body formation in the MPTP mouse model of Parkinson's disease. Mol Brain Res 2005, 134:103-108.

92. Vila M, Vukosavic S, Jackson-Lewis V, Neystat M, Jakowec M, Przedborski S: Alpha-synuclein up-regulation in substantia nigra dopaminergic neurons following administration of the parkinsonian toxin MPTP. J Neurochem 2000, 74:721-729.

93. Gibrat C, Saint-Pierre M, Bousquet M, Lévesque D, Rouillard C, Cicchetti F: Differences between subacute and chronic MPTP mice models: investigation of dopaminergic neuronal degeneration and alpha-synuclein inclusions. J Neurochem 2009, 109:1469-1482.

94. Fornai F, Schlüer OM, Lenzi P, Gesi M, Ruffoli R, Ferrucci M, Lazzeri G, Busceti CL, Pontarelli F, Battaglia G, Pellegrini A, Nicoletti F, Ruggieri S, Paparelli A, Südhof TC: Parkinson-like syndrome induced by continuous MPTP infusion: convergent roles of the ubiquitin-proteasome system and alpha-synuclein. Proc Natl Acad Sci USA 2005, 102:3413-3418.

95. Blesa J, Phani S, Jackson-Lewis V, Przedborski S: Classic and new animal models of Parkinson's disease. J Biomed Biotechnol 2012, 2012:10. Article ID 845618, doi:10.1155/2012/845618

96. Katsman Y, Foo AH, Leontyev D, Branch DR: Improved mouse models for the study of treatment modalities for immune-mediated platelet destruction. Transfusion 2010, 50:1285-1294.

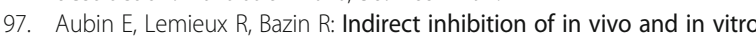
T-cell responses by intravenous immunoglobulins due to impaired antigen presentation. Blood 2010, 115:1727-1734.

98. Racz Z, Nagy E, Rosivall L, Szebeni J, Hamar P: Sugar-free, glycine-stabilized intravenous immunoglobulin prevents skin but not renal disease in the MRL/Ipr mouse model of systemic lupus. Lupus 2010, 19:599-612.

99. Gonzalez-Flores O, Gomora-Arrati P, Garcia-Juarez M, Miranda-Martinez A Armengual-Villegas A, Camacho-Arroyo I, Guerra-Araiza C: Progesterone receptor isoforms differentially regulate the expression of tryptophan and tyrosine hydroxylase and glutamic acid decarboxylase in the rat hypothalamus. Neurochem Int 2011, 59: 671-676.

100. Bosier B, Muccioli GG, Mertens B, Sarre S, Michotte Y, Lambert DM, Hermans E: Differential modulations of striatal tyrosine hydroxylase and dopamine 
metabolism by cannabinoid agonists as evidence for functional selectivity in vivo. Neuropharmacology 2012, 62:2327-2335.

101. Ferrari MFR, Coelho EF, Farizatto KLG, Chadi G, Fior-Chadi DR: Modulation of tyrosine hydroxylase, neuropeptide $Y$, glutamate, and substance $\mathrm{P}$ in ganglia and brain areas involved in cardiovascular control after chronic exposure to nicotine. Int J Hypertens 2011, 2011:1-9.

102. Dauer W, Kholodilov N, Vila M, Trillat A-C, Goodchild R, Larsen KE, Staal R, Tieu K, Schmitz Y, Yuan CA, Rocha M, Jackson-Lewis V, Hersch S, Sulzer D, Przedborski S, Burke R, Hen R: Resistance of alpha-synuclein null mice to the parkinsonian neurotoxin MPTP. Proc Natl Acad Sci USA 2002, 99:14524-14529.

103. Schluter OM, Fornai F, Alessandri MG, Takamori S, Geppert M, Jahn R, Sudhof TC: Role of alpha-synuclein in 1-methyl-4-phenyl-1,2,3,6tetrahydropyridine-induced parkinsonism in mice. Neuroscience 2003, 118:985-1002.

104. Drolet RE, Behrouz B, Lookingland KJ, Goudreau JL: Mice lacking alpha-synuclein have an attenuated loss of striatal dopamine following prolonged chronic MPTP administration. Neurotoxicology 2004, 25:761-769.

105. Robertson DC, Schmidt O, Ninkina N, Jones PA, Sharkey J, Buchman VL: Developmental loss and resistance to MPTP toxicity of dopaminergic neurones in substantia nigra pars compacta of gamma-synuclein, alpha-synuclein and double alpha/gamma-synuclein null mutant mice. Neurochem 2004, 89:1126-1136.

106. Klivenyi P, Siwek D, Gardian G, Yang L, Starkov A, Cleren C, Ferrante RJ Kowall NW, Abeliovich A, Beal MF: Mice lacking alpha-synuclein are resistant to mitochondrial toxins. Neurobiol Dis 2006, 21:541-548.

107. Papachroni KK, Ninkina N, Papapanagiotou A, Hadjigeorgiou GM, Xiromerisiou G, Papadimitriou A, Kalofoutis A, Buchman VL: Autoantibodies to alpha-synuclein in inherited Parkinson's disease. J Neurochem 2006, 101:749-756.

108. Yanamandra K, Gruden MA, Casaite V, Meskys R, Forsgren L, Morozova-Roche LA: Alpha-synuclein reactive antibodies as diagnostic biomarkers in blood sera of Parkinson's disease patients. PLoS One 2011 6:e18513.

109. He Y, Le W-D, Appel SH: Role of Fcy receptors in nigral cell injury induced by Parkinson disease immunoglobulin injection into mouse substantia nigra. Exp Neurol 2002, 176:322-327.

doi:10.1186/1742-2094-9-234

Cite this article as: St-Amour et al:: Impact of intravenous

immunoglobulin on the dopaminergic system and immune response in the acute MPTP mouse model of Parkinson's disease. Journal of

Neuroinflammation 2012 9:234.

\section{Submit your next manuscript to BioMed Central and take full advantage of:}

- Convenient online submission

- Thorough peer review

- No space constraints or color figure charges

- Immediate publication on acceptance

- Inclusion in PubMed, CAS, Scopus and Google Scholar

- Research which is freely available for redistribution 